\title{
PROFILE OF PRACTICES AND KNOWLEDGE ON STROKE AMONG POLISH EMERGENCY MEDICAL SERVICE STAFF
}

\author{
Natasza Blek ${ }^{1,2}$, Lukasz Szarpak ${ }^{2,3}$ ( \\ ${ }^{1}$ Department of Neurology, Wolski Hospital, Warsaw, Poland \\ ${ }^{2}$ Maria Sklodowska-Curie Medical Academy in Warsaw, Poland \\ ${ }^{3}$ Polish Society of Disaster Medicine, Warsaw, Poland
}

\begin{abstract}
BACKGROUND: Stroke is a leading cause of disability and death in both developed and developing countries. While hemorrhagic stroke often necessitates immediate neurosurgical intervention, ischemic stroke is treated with reperfusion therapies such as thrombolysis with intravenous recombinant tissue plasminogen activator (IV rtPA) and early endovascular thrombectomy for broad vessel occlusions.
\end{abstract}

OBJECTIVES: Early diagnoses, accurate emergency medical services (EMS) dispatch, rapid EMS transfer, and stroke team activation have helped reduce door-to-IV tPA time and continue to be critical in saving time for stroke patients' treatment.

MATERIAL AND METHODS: One reason for prehospital delays may be incorrect qualification by emergency team members due to incomplete medical records and incorrect evaluation of symptoms by dispatchers or paramedics. The dispatcher's precise identification of the report helps them decide on the patient's priority disposal of the ambulance. In comparison, a correct initial diagnosis by paramedics allows the patient to be transported immediately to the destination hospital, i.e., the unit with a stroke unit. Extending the time it takes for the patient to enter the stroke facility due to the patient being moved through stages reduces the probability of successful treatment being introduced significantly.

RESULTS: We hypothesized that paramedics' knowledge of prehospital stroke management protocols would be linked to their clinical experience as well as their stroke preparation.

CONCLUSION: A secondary goal of this study was to evaluate and compare the theoretical knowledge on stroke management among paramedics and identify factors associated with high knowledge. 468 EMS providers agreed to complete a questionnaire that included demographic questions, practical experience questions, and 14 theoretical information questions. Our research found that paramedics in Poland have significant awareness gaps in existing stroke treatment guidelines.

KEY WORDS: prehospital care, stroke, EMS, questionnaire, paramedics

Disaster Emerg Med J 2021; 6(2): 55-62

\section{INTRODUCTION}

Stroke is a significant cause of disability and mortality in developed and developing countries [1]. About $80-90 \%$ of cerebrovascular incidents are caused by ischemic stroke [2], which the most critical etiologies include large artery atherosclerosis (macroangiopathy), cardioembolism, and small-vessel cerebral disorder (microangiopathy).

So although hemorrhagic stroke frequently needs immediate neurosurgical intervention, ischemic 
stroke is treated with reperfusion therapies such as thrombolysis with intravenous recombinant tissue plasminogen activator (IV rtPA) and early endovascular thrombectomy for large vessel occlusions. Both methods are intended to recanalize the obstructed artery efficiently, preserve normal blood supply and, as a result, reperfuse brain tissue. Therefore, the central aspect preventing the usage of both thrombolytic treatment and mechanical thrombectomy in ischemic stroke is that both forms of therapy have a brief utilization period.

Early identification, accurate emergency medical services (EMS) dispatch, quick EMS transfer, and stroke team activation have helped to minimize door-to-IV tPA time and remain vital in saving time for the care of stroke patients [3].

Until 2021, the recommended treatment window was limited to $4.5 \mathrm{~h}$ for intravenous alteplase and 6-24 h for thrombectomy. Recent experiments have expanded these windows to patients chosen by imaging and have modified the definition from a set to an individual treatment window [4].

Additionally, as the time between the onset of stroke symptoms and the start of treatment increases, cerebral thrombolysis's effectiveness decreases. In mechanical thrombectomy, its drawbacks are the high cost of therapy and the probability of conducting it only in highly specialized facilities and a similarly restricted time window. Unfortunately, in 44 European countries, stroke authorities reported that only 7.3 percent of ischemic stroke cases underwent intravenous thrombolysis $(95 \% \mathrm{Cl}$ 5.4-9.1), and 1.9\% underwent endovascular therapy [5]. Therefore, the earliest possible completion of therapy and the prevention of undue delays remain a crucial component of clinical success in the stroke's acute phase.

\section{Symptom detection by medical staff}

One explanation for the incidence of prehospital delays may be incorrect qualification by emergency team personnel, resulting from inaccurate medical records and inaccurate diagnosis of symptoms by dispatchers or paramedics. The dispatcher's specific identification of the report allows deciding on the patient's priority disposal of the ambulance. In contrast, paramedics' proper initial diagnosis allows the patient to be transported directly to the destination facility, i.e. the unit with a stroke unit. Extending the time, it takes for the patient to reach the stroke facility, resulting from the patient being transferred across stages, dramatically decreases the likelihood of successful treatment being introduced.

To ensure proper prehospital treatment of suspected brain stroke and transportation to a specialist stroke unit, the Ministry of Health, in collaboration with State consultants in neurology and emergency medicine, issued guidelines on January 24th, 2019 - the so-called "Good praxis in treating patients with suspected brain stroke for medical dispatchers and EMS teams".

\section{Study design}

\section{MATERIAL AND METHODS}

The study was approved by the Institutional Review Board of the Polish Society of Disaster Medicine (approval No. 10.10.2020.IRB).

The questionnaire was developed using NB and $Ł S z$ clinical expertise and was validated in a pilot study conducted in December 2020 in Warsaw, Poland. The comments of the participating EMS members were used to improve the wording of some items in the questionnaire and eliminate redundant questions. The pilot study also allowed to determine the time needed to complete the questionnaire.

The final version of the survey asked EMS providers about demographics, their practices - methods to identify stroke, ambulance management, the information they provide for prenotification, how often they prenotify hospital EDs of an incoming suspected stroke patient, and knowledge questions — such as the time windows for IV tPA administration and mechanical thrombectomy, stroke symptoms, and mimics.

The questionnaire consisted of both closed-ended and open-ended questions, using a combination of Likert scales, single- and multiple-choice questions, and free text fields to enable the collection of both qualitative and quantitative data. Participants were scored based on several correct answers. A scoring system was devised, with each correct answer earning one point and no negative marking. Every participant has graded a total score ( 0 being the lowest and 14 being the highest possible score).

\section{Recruitment}

A web link to the survey was sent by e-mail to members of the Polish Society of Disaster Medicine and the promotion of the survey on social media. The 
survey was open for six weeks between January 1st, 2021, and February 15th, 2021.

\section{STATISTICAL ANALYSIS}

Statistical analysis was performed with the Statistical Package for Social Science (SPSS) version 27.0 software (SPSS, Inc., Chicago, IL, USA). We classified participants into less experienced (up to 10 years of professional experience) and more experienced (10 and more years of professional experience). Descriptive statistics were used to summarize the baseline characteristics of each group. Demographics were categorized by gender, years of experience, workplace, monthly duties, and the number of interventions in stroke patients per month.

Descriptive statistics were used to describe survey responses. Frequencies and proportions were used to describe categorical variables. Responses to open-ended questions were grouped and described using frequencies and proportions.

\section{RESULTS}

\section{Demographics, professional experience}

A total of 468 EMS providers completed the survey. Of the participants, $239(51 \%)$ were less experienced EMS providers, and 229 (49\%) were more experienced. The mean age of the participants was $34(\mathrm{SD}=7.33)$ years, and $402(86 \%)$ participants were men, which corresponds to the male predominance in the profession. The majority of participants reported previous attendance to stroke workshops/courses (55\%) and performed less than 5 stroke patient interventions per month (64\%). Most of the responders work in the ambulance services and have less than 15 duties per month (60\%). Demographic and descriptive information are summarized in Table 1.

\section{Confidence level regarding interventions}

Regarding confidence level, only $30 \%$ of the respondents reported that they felt very confident (value $=5$ ) in their ability to recognize an adult patient in stroke. Table 2 summarizes confidence levels compared to the other neurological conditions.

\section{Practices}

\section{Prenotification practice}

According to the American Heart Association/American Stroke Association (AHA/ASA) guidelines [6], the

\begin{tabular}{|c|c|c|}
\hline & & $\mathrm{n}(\%)$ \\
\hline \multirow[t]{2}{*}{ Gender } & male & $402(86 \%)$ \\
\hline & female & $66(14 \%)$ \\
\hline \multirow{2}{*}{$\begin{array}{l}\text { Stroke patient } \\
\text { interventions per month }\end{array}$} & less than 5 & $300(64 \%)$ \\
\hline & 5 and more & $168(36 \%)$ \\
\hline \multirow{2}{*}{$\begin{array}{l}\text { Has attended } \\
\text { workshops/courses } \\
\text { on stroke patient } \\
\text { management }\end{array}$} & yes & $258(55 \%)$ \\
\hline & no & $210(45 \%)$ \\
\hline \multirow{5}{*}{$\begin{array}{l}\text { Years of professional } \\
\text { experience }\end{array}$} & $11-15$ years & $126(27 \%)$ \\
\hline & $1-5$ years & $120(26 \%)$ \\
\hline & $6-10$ years & $102(22 \%)$ \\
\hline & more than 15 years & 90 (19\%) \\
\hline & less than one year & $30(6.4 \%)$ \\
\hline \multirow[t]{3}{*}{ Workplace } & ambulance services & $432(92 \%)$ \\
\hline & other & $18(3.8 \%)$ \\
\hline & ED & $18(3.8 \%)$ \\
\hline \multirow[t]{2}{*}{ Monthly duties } & less than 15 & $282(60 \%)$ \\
\hline & 15 and more & $186(40 \%)$ \\
\hline
\end{tabular}

Table 2. Confidence levels regarding interventions

\begin{tabular}{|l|c|c|}
\hline \multicolumn{1}{|c|}{ Confidence } & mean (SD) & $\mathrm{n}$ \\
\hline Unconscious patient & $4.10(0.633)$ & 468 \\
\hline Stroke patient & $4.25(0.545)$ & 468 \\
\hline Patient with traumatic brain injury & $3.91(0.629)$ & 468 \\
\hline Patient with epilepsy & $4.32(0.631)$ & 468 \\
\hline
\end{tabular}

SD - Standard Deviation

duty physician, a neurologist of the required facility to whom the patient is delivered, should be told by telephone by the EMS or dispatcher about the patient's age, health diagnosis and symptoms, time of disease, and expected delivery time (prenotification).

Ideally, the EMS can send these details directly to the neurologist on duty as it enables having the most detailed patient records possible at the prehospital level.

Prenotification allows pre-registration of patient details in the goal hospital's database system.

These procedures significantly decrease the duration of early hospital administration for a patient with ischemic stroke, allowing the patient to be planned for admission (the so-called stroke alert) and the stroke unit practitioner to schedule advance access to hospital identification, laboratory, and brain imaging test instructions, as well as Ac- 
cess to electronically accessible hospital and outpatient medical history. Only $63 \%$ of participants who prenotify hospital staff includes all the necessary information listed in the guidelines.

\section{Stroke assessment scales}

FAST was the most commonly used stroke assessment tool and is currently supported by national recommendations. Sensitivities for FAST ranged from 0.64 to 0.97 in four trials, with a summary estimated sensitivity of 0.86 , according to a new Systematic Review reviewing the accuracy of clinical instruments for acute stroke assessment [7].

\section{Management of hypoglycemia}

According to AHAJASA and European Stroke Organisation (ESO) $[6,8]$, since symptoms of hypoglycemia can resemble those of a stroke, blood glucose should be tested in any patient with a suspected stroke. Hypoglycemia (defined as blood glucose $<60 \mathrm{mg} / \mathrm{dL}$ ) should be treated in patients with acute ischemic stroke with glucose $20-40 \%$ in $25-50 \mathrm{ml}$ infusion [9]. $76.3 \%$ of surveyed participants did not know the current recommendations - the most common mistake was the correction of hyperglycemia during ambulance transfer.

\section{Management of hypertension}

AHA/ASA and ESO guidelines for prehospital management of stroke highlight that also with systolic blood pressure near $185 \mathrm{mmHg}$, which can increase door to needle time, paramedics' immediate prehospital antihypertensive care presents a risk of unexpected decreases in blood pressure; thus, elevated blood pressure care in the prehospital period should be avoided. Almost $80 \%$ of paramedics could not provide an answer in line with current guidelines - with decreasing hypertension in the prehospital level being the most common mistake.

\section{Knowledge}

Respondents performed well on questions testing general knowledge of stroke - etiology, risk factors, pathophysiology, symptoms, types, components of the FAST scale. They also knew the differences between types of facilities that hospitalize stroke patients. An unsatisfactory percentage of respondents gave correct answers to topics related to stroke mimics, time windows for thrombolytic treatment and thrombectomy, and different stages of the survival chain.

\begin{tabular}{|c|c|c|}
\hline Practice & Answer & $\mathrm{n}(\%)$ \\
\hline \multirow[t]{4}{*}{ Prenotification } & always & $324(69 \%)$ \\
\hline & often & $108(23 \%)$ \\
\hline & rarely & $24(5.1 \%)$ \\
\hline & never & $12(2.6 \%)$ \\
\hline \multirow{2}{*}{$\begin{array}{l}\text { Prenotification } \\
\text { data }\end{array}$} & according to the guidelines & $294(63 \%)$ \\
\hline & $\begin{array}{l}\text { not according to the } \\
\text { guidelines }\end{array}$ & $174(37 \%)$ \\
\hline \multirow{6}{*}{$\begin{array}{l}\text { Prehospital } \\
\text { scale used }\end{array}$} & FAST & $228(49 \%)$ \\
\hline & not using any & $162(35 \%)$ \\
\hline & both FAST and CPSS & $36(7.7 \%)$ \\
\hline & both FAST and LAPSS & $30(6.4 \%)$ \\
\hline & LAPSS & $6(1.3 \%)$ \\
\hline & both CPSS and LAPSS & $6(1.3 \%)$ \\
\hline \multirow{2}{*}{$\begin{array}{l}\text { Management } \\
\text { of } \\
\text { Hypertension }\end{array}$} & $\begin{array}{l}\text { not according to the } \\
\text { guidelines }\end{array}$ & $376(80 \%)$ \\
\hline & according to the guidelines & $92(20 \%)$ \\
\hline \multirow[t]{2}{*}{$\begin{array}{l}\text { Management } \\
\text { of Glycaemia }\end{array}$} & $\begin{array}{l}\text { not according to the } \\
\text { guidelines }\end{array}$ & $351(76.3 \%)$ \\
\hline & according to the guidelines & $111(24 \%)$ \\
\hline
\end{tabular}

\begin{tabular}{|c|c|c|}
\hline Task & Answer & $\mathrm{n}(\%)$ \\
\hline \multirow{2}{*}{$\begin{array}{l}\text { Correctly identified stroke } \\
\text { etiology }\end{array}$} & correct & $294(63 \%)$ \\
\hline & incorrect & $174(37 \%)$ \\
\hline \multirow{2}{*}{$\begin{array}{l}\text { Knew difference between two } \\
\text { types of stroke facilities }\end{array}$} & correct & $312(67 \%)$ \\
\hline & incorrect & $156(33 \%)$ \\
\hline \multirow{2}{*}{$\begin{array}{l}\text { Correctly identified at least } 11 \\
\text { stroke symptoms }\end{array}$} & correct & $348(74 \%)$ \\
\hline & incorrect & $120(26 \%)$ \\
\hline \multirow[t]{2}{*}{ Knew FAST scale components } & correct & $240(51 \%)$ \\
\hline & incorrect & $228(49 \%)$ \\
\hline \multirow{2}{*}{$\begin{array}{l}\text { Correctly identified ischemic } \\
\text { stroke types }\end{array}$} & correct & $402(86 \%)$ \\
\hline & incorrect & $66(14 \%)$ \\
\hline \multirow{2}{*}{$\begin{array}{l}\text { Correctly identified components } \\
\text { of stroke chain of survival }\end{array}$} & incorrect & $258(55 \%)$ \\
\hline & correct & $210(45 \%)$ \\
\hline \multirow{2}{*}{$\begin{array}{l}\text { Correctly named at least four- } \\
\text { stroke mimics }\end{array}$} & incorrect & $270(58 \%)$ \\
\hline & correct & $198(42 \%)$ \\
\hline \multirow{2}{*}{$\begin{array}{l}\text { Knew time window for } \\
\text { thrombolysis }\end{array}$} & incorrect & $307(66 \%)$ \\
\hline & correct & $161(34 \%)$ \\
\hline \multirow{2}{*}{$\begin{array}{l}\text { Knew time window for } \\
\text { thrombectomy }\end{array}$} & incorrect & $245(52 \%)$ \\
\hline & correct & $223(48 \%)$ \\
\hline \multirow{2}{*}{$\begin{array}{l}\text { Correctly developed FAST } \\
\text { acronym }\end{array}$} & correct & $338(72 \%)$ \\
\hline & incorrect & $130(28 \%)$ \\
\hline
\end{tabular}




\section{Stroke chain of survival}

As with the Chain of Survival, which is used to describe the sequence of events necessary to survive sudden cardiac death [10], the Chain of Recovery is a metaphor for the series of events that must occur during the emergency care of the possible stroke victim to maximize his or her chances of complete recovery [11]. The chain's critical links include the following: 1. Patient or bystander recognition of stroke symptoms; 2. Immediate activation of the Emergency Medical System (EMS) and proper dispatch with pre-arrival instructions; 3. Emergency medical response, assessment, evacuation, and appropriate prehospital care promptly; 4 . Prenotifying the receiving stroke center to prepare and mobilize resources; 5. Rapid definitive diagnosis at a stroke center by experienced specialists.

The Chain of Recovery has been renamed the "Stroke Chain of Survival" in American Heart Association publications. The chain is made up of eight links, which are labeled the "Ds of stroke care" (detection, dispatch, delivery, door, data, decision, drug, and disposition) [9].

\section{Stroke mimics}

Stroke mimic is a non-vascular disease characterized by acute neurological deficits comparable to those associated with stroke. According to several small studies, up to one-third of patients evaluated acutely by a stroke team and up to $15 \%$ of patients treated with intravenous tissue plasminogen activator (t-PA) have such stroke mimics; possible etiologies include seizures, tumors, migraine, infections, delirium, peripheral nerve injuries, multiple sclerosis, and conversion disorders [12-14].

\section{Time window - thrombolysis}

Intravenous thrombolysis with alteplase is currently the standard treatment for acute ischemic stroke. IVT with alteplase remains the standard treatment within the 4.5 hours window after symptoms' onset. It is worth mentioning that after the survey was already disseminated, ESO issued the newest guidelines. High-quality evidence was found to recommend intravenous thrombolysis with alteplase to improve functional outcomes in patients with acute ischemic stroke within $4.5 \mathrm{~h}$ after symptom onset. Intravenous thrombolysis with alteplase is also recommended in patients with acute ischemic stroke on awakening from sleep, who were last seen well more than $4.5 \mathrm{~h}$ earlier, who have MRI DWI-FLAIR mismatch, and for whom mechanical thrombectomy is not planned [4].

\section{Time window - thrombectomy}

Mechanical thrombectomy (MT) is the gold standard of care for acute ischemic stroke (AIS) caused by anterior circulation large vessel occlusion within six hours of symptom onset and can be extended to 24 hours in selected patients [8].

\section{High knowledge factors}

To identify potential associations between high knowledge and demographic characteristics, we carried out a linear regression, with the outcome variable of total test score and the explanatory variables of experience, number of stroke interventions per month, previous attendance at workshops, number of monthly duties, and level of self-confidence regarding stroke.

We selected the candidate covariates from the set of collected variables so that there were less than $20 \%$ of participants with missing data or variables with less than $5 \%$ missing values. The covariates of experience, number of stroke interventions per month, previous attendance at workshops, number of monthly duties, and level of self-confidence regarding stroke were defined a priori based on data from the literature.

Participants were divided into two groups depending on their level of experience. We discovered that paramedics with less than 11 years of experience were more knowledgeable about stroke treatment than their senior colleagues. One potential reason for this disparity is that these junior employees have received their training more recently and up to date with guidelines. Our findings suggest where educational efforts should be focused on the national rising stroke burden and the improving availability of thrombolysis and thrombectomy.

With a $5 \%$ risk, by adjusting for the number of stroke interventions per month, previous attendance at workshops, number of monthly duties, and level of self-confidence regarding stroke, there is a statistically significant relationship between total test score and experience. Results of the logistic regression are presented in Table 6.

\section{DISCUSSION}

This survey's findings give a brief overview of paramedics' practices and knowledge regarding prehos- 


\begin{tabular}{|c|c|c|c|c|c|c|}
\hline & & $\begin{array}{c}\text { Experience }- \text { less than } \\
11 \text { years }(n=239)\end{array}$ & $\begin{array}{l}\text { Experience }-11 \text { years } \\
\text { and more }(n=229)\end{array}$ & $\mathrm{n}$ & $\mathrm{p}$ & test \\
\hline Total test score, mean & & $7.91( \pm 2.14)$ & $6.76( \pm 2.35)$ & 468 & $<0.001$ & Welch \\
\hline Age, mean & & $28.8( \pm 3.38)$ & $39.3( \pm 6.40)$ & 468 & $<0.001$ & Welch \\
\hline \multirow[t]{2}{*}{ Gender, n } & Male & $208(87 \%)$ & $194(85 \%)$ & 402 & \multirow[t]{2}{*}{0.47} & \multirow[t]{2}{*}{ Chi2 } \\
\hline & Female & $31(13 \%)$ & $35(15 \%)$ & 66 & & \\
\hline \multirow{2}{*}{$\begin{array}{l}\text { Stroke patient cases per } \\
\text { month }\end{array}$} & Less than 5 & $151(63 \%)$ & $149(65 \%)$ & 300 & \multirow[t]{2}{*}{0.67} & \multirow[t]{2}{*}{ Chi2 } \\
\hline & 5 and more & $88(37 \%)$ & $80(35 \%)$ & 168 & & \\
\hline \multirow{2}{*}{$\begin{array}{l}\text { Has attended workshops/ } \\
\text { /courses on stroke patient } \\
\text { management }\end{array}$} & Yes & $100(42 \%)$ & $158(69 \%)$ & 258 & \multirow[t]{2}{*}{$<0.001$} & \multirow[t]{2}{*}{ Chi2 } \\
\hline & No & $139(58 \%)$ & $71(31 \%)$ & 210 & & \\
\hline \multirow[t]{4}{*}{ Practice - prenotification, $\mathrm{n}$} & Always & $165(69 \%)$ & $159(69 \%)$ & 324 & \multirow[t]{4}{*}{$<0.01$} & \multirow[t]{4}{*}{ Chi2 } \\
\hline & Often & $56(23 \%)$ & $52(23 \%)$ & 108 & & \\
\hline & Rarely & $7(2.9 \%)$ & $17(7.4 \%)$ & 24 & & \\
\hline & Never & $11(4.6 \%)$ & $1(0.44 \%)$ & 12 & & \\
\hline \multirow[t]{2}{*}{ Prenotification data } & $\begin{array}{l}\text { According to the } \\
\text { guidelines }\end{array}$ & $188(79 \%)$ & $106(46 \%)$ & 294 & \multirow[t]{2}{*}{$<0.001$} & \multirow[t]{2}{*}{ Chi2 } \\
\hline & $\begin{array}{l}\text { Not according to } \\
\text { the guidelines }\end{array}$ & $51(21 \%)$ & $123(54 \%)$ & 174 & & \\
\hline \multirow[t]{2}{*}{$\begin{array}{l}\text { Management of } \\
\text { Hypertension }\end{array}$} & $\begin{array}{c}\text { Not according to } \\
\text { the guidelines }\end{array}$ & $203(85 \%)$ & $173(76 \%)$ & 376 & \multirow[t]{2}{*}{0.011} & \multirow[t]{2}{*}{ Chi2 } \\
\hline & $\begin{array}{l}\text { According to the } \\
\text { guidelines }\end{array}$ & $36(15 \%)$ & $56(24 \%)$ & 92 & & \\
\hline \multirow[t]{2}{*}{ Management of Glycaemia, n } & $\begin{array}{l}\text { Not according to } \\
\text { the guidelines }\end{array}$ & $183(76.5 \%)$ & $174(76 \%)$ & 351 & \multirow[t]{2}{*}{0.055} & \multirow[t]{2}{*}{ Chi2 } \\
\hline & $\begin{array}{l}\text { According to the } \\
\text { guidelines }\end{array}$ & $56(23 \%)$ & $55(24 \%)$ & 111 & & \\
\hline \multirow[t]{2}{*}{ Monthly duties } & less than 15 & $144(60 \%)$ & $138(60 \%)$ & 282 & \multirow[t]{2}{*}{1} & \multirow[t]{2}{*}{ Chi2 } \\
\hline & 15 and more & $95(40 \%)$ & $91(40 \%)$ & 186 & & \\
\hline \multirow[t]{5}{*}{ Confidence - stroke, $n$} & 3 & $21(8.8 \%)$ & $5(2.2 \%)$ & 26 & \multirow[t]{5}{*}{$<0.01$} & \multirow[t]{5}{*}{ Chi2 } \\
\hline & 4 & $157(66 \%)$ & $144(63 \%)$ & 301 & & \\
\hline & 5 & $61(26 \%)$ & $80(35 \%)$ & 141 & & \\
\hline & 4 & $114(48 \%)$ & $120(52 \%)$ & 234 & & \\
\hline & 5 & $95(40 \%)$ & $97(42 \%)$ & 192 & & \\
\hline
\end{tabular}

Table 6. Results of the logistic regression
\begin{tabular}{|l|c|c|c|c|}
\hline & & Coefficients & $p$ & $p$ global \\
\hline Professional experience & Ten years and more vs. less than ten years & $-1.29(-1.70 ;-0.885)$ & $<0.001$ & $<0.001$ \\
\hline Stroke patient cases per month & Five and more vs. less than 5 & $0.882(0.477 ; 1.29)$ & $<0.001$ & $<0.001$ \\
\hline $\begin{array}{l}\text { Has attended workshops/courses on } \\
\text { stroke patient management }\end{array}$ & No vs. yes & $-0.209(-0.614 ; 0.196)$ & 0.31 & 0.31 \\
\hline Monthly duties & 15 and more vs. less than 15 & $0.824(0.420 ; 1.23)$ & $<0.001$ & $<0.001$ \\
\hline Confidence level - stroke & 4 vs. 3 & $0.479(-0.385 ; 1.34)$ & 0.28 & $<0.01$ \\
\hline & 5 vs. 3 & $1.20(0.294 ; 2.11)$ & $<0.01$ & \\
\hline
\end{tabular}


pital stroke management. It is the first time a survey of this kind has been conducted in Poland. A few other interventional studies have tried to evaluate and then increase the expertise of the paramedic in a variety of methods, including training programs $[15,16]$. The online training intervention conducted in Catalonia was successful in raising EMS professionals' awareness and prenotification compliance at stroke code activation and in achieving widespread adoption of a new prehospital stroke severity assessment scale (i.e., the RACE scale) [17]. In a study conducted by Hsieh et al., the 1-hour course presented basic stroke knowledge, such as stroke epidemiology, symptoms, diagnosis, treatment, and determining onset time [18]. The educational program increased knowledge about stroke and improved the accuracy of triage by dedicated EMS providers. When assessed immediately after the intervention, an educational lecture proved successful in enhancing stroke awareness in a similar study conducted in Dubai [19]. However, there is a need to re-evaluate paramedics' knowledge at regular intervals to determine the need for prehospital stroke management refresher courses.

\section{Limitations of the study}

This study has several limitations. Surveys are not knowledge tests, and respondents may not give a survey answer the same consideration that they would give to a knowledge examination; thus, the percentage of correct answers may not accurately reflect the survey participants' knowledge. Furthermore, respondents may provide answers that they believe are correct but do not reflect actual practice. Furthermore, responding to questions in a survey may not accurately reflect how one would respond in the field. The use of a convenience sample, which introduces the possibility of selection bias is another of the study's limitations. If survey participants did not respond because they were unsure of the correct answer, our findings might understate the number of incorrect answers and lack of stroke management knowledge.

\section{CONCLUSION}

This study has shown that in Polish paramedics' stroke knowledge is suboptimal and deficient regarding current prehospital guidelines. With recent advances in stroke care and the lack of education on stroke after initial training, it is not surprising that paramedics are unaware of existing procedures and the vital role they currently play in stroke care. The results of this study indicate the need to change paramedic education, the importance of combining education with prehospital stroke care in stroke detection by paramedics, and the need to prenotify patients within the window of care for thrombolytic and endovascular treatment.

\section{REFERENCES}

1. Feigin VL, Norrving Bo, Mensah GA, et al. Global Burden of Diseases, Injuries and Risk Factors Study 2013 and Stroke Experts Writing Group, GBD 2013 Stroke Panel Experts Group, GBD 2013 Stroke Panel Experts Group, RIBURST Study Collaboration Writing Group. New strategy to reduce the global burden of stroke. Stroke. 2015; 46(6): 1740-1747, doi: 10.1161/STROKEAHA.115.008222, indexed in Pubmed: 25882050.

2. Benjamin E, Blaha M, Chiuve S, et al. Heart Disease and Stroke Statistics-2017 Update: A Report From the American Heart Association. Circulation. 2017; 135(10), doi: 10.1161/cir.0000000000000485.

3. Puolakka T, Kuisma M, Länkimäki $S$, et al. Cutting the Prehospital On-Scene Time of Stroke Thrombolysis in Helsinki: A Prospective Interventional Study. Stroke. 2016; 47(12): 3038-3040, doi: 10.1161/STROKEAHA.116.014531, indexed in Pubmed: 27827326.

4. Berge $E$, Whiteley $W$, Audebert $H$, et al. European Stroke Organisation (ESO) guidelines on intravenous thrombolysis for acute ischaemic stroke. Eur Stroke J. 2021; 6(1): I-LXII, doi: 10.1177/2396987321989865, indexed in Pubmed: 33817340.

5. Aguiar de Sousa D, von Martial R, Abilleira $S$, et al. Access to and delivery of acute ischaemic stroke treatments: A survey of national scientific societies and stroke experts in 44 European countries. Eur Stroke J. 2019; 4(1): 13-28, doi: 10.1177/2396987318786023, indexed in Pubmed: 31165091.

6. Kobayashi A, Czlonkowska A, Ford GA, et al. European Academy of Neurology and European Stroke Organization consensus statement and practical guidance for pre-hospital management of stroke. Eur J Neurol. 2018; 25(3): 425-433, doi: 10.1111/ene.13539, indexed in Pubmed: 29218822.

7. Meyran D, Cassan P, Avau B, et al. Stroke Recognition for First Aid Providers: A Systematic Review and Meta-Analysis. Cureus. 2020; 12(11): e11386, doi: 10.7759/cureus.11386, indexed in Pubmed: 33312787.

8. Powers WJ, Rabinstein AA, Ackerson T, et al. Guidelines for the Early Management of Patients With Acute Ischemic Stroke: 2019 Update to the 2018 Guidelines for the Early Management of Acute Ischemic Stroke: A Guideline for Healthcare Professionals From the American Heart Association/American Stroke Association. Stroke. 2019; 50(12): e344-e418, doi: 10.1161/STR.0000000000000211, indexed in Pubmed: 31662037.

9. Jauch EC, Saver JL, Adams HP, et al. American Heart Association Stroke Council, Council on Cardiovascular Nursing, Council on Peripheral Vascular Disease, Council on Clinical Cardiology. Guidelines for the 
early management of patients with acute ischemic stroke: a guideline for healthcare professionals from the American Heart Association/ American Stroke Association. Stroke. 2013; 44(3): 870-947, doi: 10.1161/STR.0b013e318284056a, indexed in Pubmed: 23370205.

10. Panchal AR, Berg KM, Cabañas JG, et al. 2019 American Heart Association Focused Update on Systems of Care: Dispatcher-Assisted Cardiopulmonary Resuscitation and Cardiac Arrest Centers: An Update to the American Heart Association Guidelines for Cardiopulmonary Resuscitation and Emergency Cardiovascular Care. Circulation. 2019; 140(24): e895-e903, doi: 10.1161/CIR.0000000000000733, indexed in Pubmed: 31722563.

11. Pepe PE, Zachariah BS, Sayre MR, et al. Ensuring the chain of recovery for stroke in your community. Chain of Recovery Writing Group. Prehosp Emerg Care. 1998; 2(2): 89-95, doi: 10.1080/10903129808958849, indexed in Pubmed: 9709325.

12. McClelland $G$, Rodgers $H$, Flynn $D$, et al. The frequency, characteristics and aetiology of stroke mimic presentations: a narrative review. Eur J Emerg Med. 2019; 26(1): 2-8, doi: 10.1097/MEJ.0000000000000550, indexed in Pubmed: 29727304.

13. Hansson PO, Andersson Hagiwara M, Herlitz J, et al. Prehospital assessment of suspected stroke and TIA: An observational study. Acta Neurol Scand. 2019; 140(2): 93-99, doi: 10.1111/ane.13107, indexed in Pubmed: 31009075.

14. H Buck B, Akhtar N, Alrohimi A, et al. Stroke mimics: incidence, aetiology, clinical features and treatment. Ann Med. 2021; 53(1):
420-436, doi: 10.1080/07853890.2021.1890205, indexed in Pubmed: 33678099.

15. Behrens S, Daffertshofer $M$, Interthal C, et al. Improvement in stroke quality management by an educational programme. Cerebrovasc Dis. 2002; 13(4): 262-266, doi: 10.1159/000057853, indexed in Pubmed: 12011551.

16. Wojner-Alexandrov AW, Alexandrov AV, Rodriguez D, et al. Houston paramedic and emergency stroke treatment and outcomes study (HoPSTO). Stroke. 2005; 36(7): 1512-1518, doi: 10.1161/01.STR.0000170700.45340.39, indexed in Pubmed: 15961712.

17. Gorchs-Molist M, Solà-Muñoz S, Enjo-Perez I, et al. An Online Training Intervention on Prehospital Stroke Codes in Catalonia to Improve the Knowledge, Pre-Notification Compliance and Time Performance of Emergency Medical Services Professionals. Int J Environ Res Public Health. 2020; 17(17), doi: 10.3390/ijerph17176183, indexed in Pubmed: 32858885.

18. Hsieh HC, Hsieh CY, Lin CH, et al. Development of an educational program for staffs of emergency medical service to improve their awareness of stroke within 3 hours of symptom onset: a pilot study. Acta Neurol Taiwan. 2013; 22(1): 4-12, indexed in Pubmed: 23479240.

19. Shire F, Kasim Z, Alrukn S, et al. Stroke awareness among Dubai emergency medical service staff and impact of an educational intervention. BMC Res Notes. 2017; 10(1): 255, doi: 10.1186/s13104-017-2585-x, indexed in Pubmed: 28683821. 